\title{
The Australian Experiment: How Primary Health Care Organizations Supported the Evolution of a Primary Health Care System
}

\author{
Caroline Nicholson, MBA, GAICD, GradDipPhty \\ Claire L. Jackson, MD, MBBS, MPH, FRACGP, John E. Marley, MD, MBChB, FRACGP \\ and Robert Wells, BA
}

Primary health care in Australia has undergone 2 decades of change. Starting with a vision for a national health strategy with general practice at its core, Australia established local meso-level primary health care organizations-Divisions of General Practice-moving from focus on individual practitioners to a professional collective local voice.

The article identifies how these meso-level organizations have helped the Australian primary health care system evolve by supporting the roll-out of initiatives including national practice accreditation, a focus on quality improvement, expansion of multidisciplinary teams into general practice, regional integration, information technology adoption, and improved access to care. Nevertheless, there are still challenges to ensuring equitable access and the supply and distribution of a primary care workforce, addressing the increasing rates of chronic disease and obesity, and overcoming the fragmentation of funding and accountability in the Australian system. (J Am Board Fam Med 2012;25:S18-26.)

Keywords: Australia, Health Care Reform, Primary Health Care

The Australian Federation health system has a mix of federal (Commonwealth Department of Health \& Ageing) and state government funding and control, with service provision through private and public sectors. Under the national universal health insurance system (Medicare), all Australians are guaranteed free treatment based on clinical need in public hospitals (operated by the states) with subsidized access to primary care, private specialist

\footnotetext{
This article was externally peer reviewed.

Submitted 11 July 2011; revised 3 November 2011; accepted 21 November 2011.

From the Mater/UQ Centre for Primary Health Care Innovation, Mater Health Services, South Brisbane, Queensland, Australia (CN); Discipline of General Practice, the University of Queensland (CLJ); Faculty of Health Sciences, the University of Queensland (JEM); and Australian Primary Health Care Research Institute, Australian National University (RW). the University of Queensland (CLJ, JEM); and the Australian National University (RW).

Funding: none.

Conflict of interest: none declared.

Corresponding author: Caroline Nicholson, Director, Mater/UQ Centre for Primary Health Care Innovation, Mater Health Services, Raymond Terrace, South Brisbane, Queensland 4101, Australia (E-mail: Caroline.Nicholson@ mater.org.au).
}

care (including diagnostics), and pharmaceuticals (Figure 1). ${ }^{1}$ General practitioners (GPs) have a gatekeeping role to specialist care because Medicare only reimburses specialists the scheduled fee for payment for referred consultations. States also provide some specialized primary care services, including drug and alcohol addiction care and infectious diseases (Figure 1). Australia spends approximately $9 \%$ to $10 \%$ of gross domestic product on health, split approximately 70\%:30\% public:private.

\section{Primary Health Care}

The last 2 decades have provided international evidence that a strong primary health care (PHC) system improves health outcomes, reduces costs and health inequities, and increases patient satisfaction. ${ }^{2,3}$ This underpins the emphasis being placed on $\mathrm{PHC}$ by government reform processes. ${ }^{4}$

A critical building block to support significantly enhanced health service responsibilities built around a stable general practice sector was forged in 1992 with the "National Health Strategy: the Future of Gen- 
Figure 1. The structure of the Australian health care system and its flow of funds. *The tax rebate is not an expense of the Australian Government Department of Health and Ageing, but is a tax expenditure of the Australian Government. Source: Australian Institute of Health and Welfare 2007. Health expenditure Australia 2005-06. Health and Welfare Expenditure series no. 30. Cat. No. HWE 37. Canberra: AIHW.

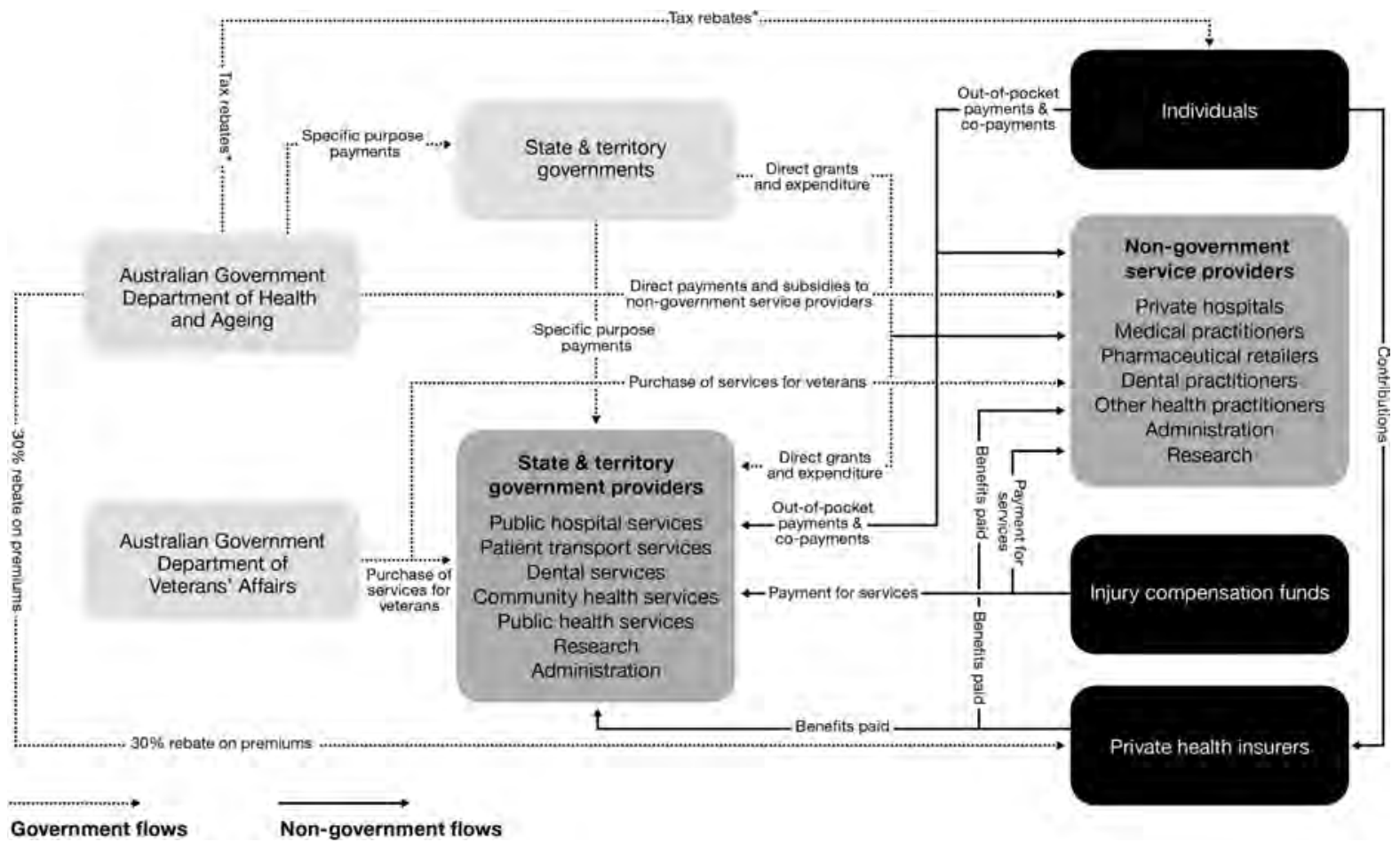

eral Practice." 5 This promoted a holistic model of care, practice accreditation to Royal Australian College of General Practice standards, a blended payment model to encourage non-fee-for-service activity, growth in service integration with professionals and services outside the practice, and funding support for information technology. In 2010 Australia launched its first national PHC strategy, ${ }^{6}$ identifying regional integration, information technology including e-health, improved access and reduced inequity, chronic disease management, prevention, improved infrastructure development, and a focus on quality, safety, performance, and accountability as key building blocks and priority areas.

Today the Australian health system performs well against other OECD countries; for example, Australia, Italy, Canada, and Japan, were identified as an OECD league table leader in the category of 15 -year survival for 45 -year-old women. ${ }^{7}$ It is supported by a primary care sector that strives to provide holistic, comprehensive, coordinated, efficient, and accessible health care. ${ }^{8}$ Australia places top in almost all primary care-related measures, including prevention, avoidable deaths, smoking abstention, efficiency, coverage, patient satisfaction, use of electronic medical records, and longevity. ${ }^{9}$

The purpose of this article is to describe Australian innovations and investments in the PHC system, how these have helped with its evolution, and their position and functions within the Australian health system. We also highlight ongoing challenges.

\section{Methods}

This article is a narrative ${ }^{10}$ of how the introduction of Australian primary health care organizations (PHCOs) — the "experiment" — has been instrumental in transforming the PHC landscape. Review questions included, How did the implementation of PHCOs in the Australian PHC system create opportunity for adoption of some of the key PHC features (Table 1)? What is an effective health care governance model for integrated primary/secondary care in Australia? What are the future challenges? 


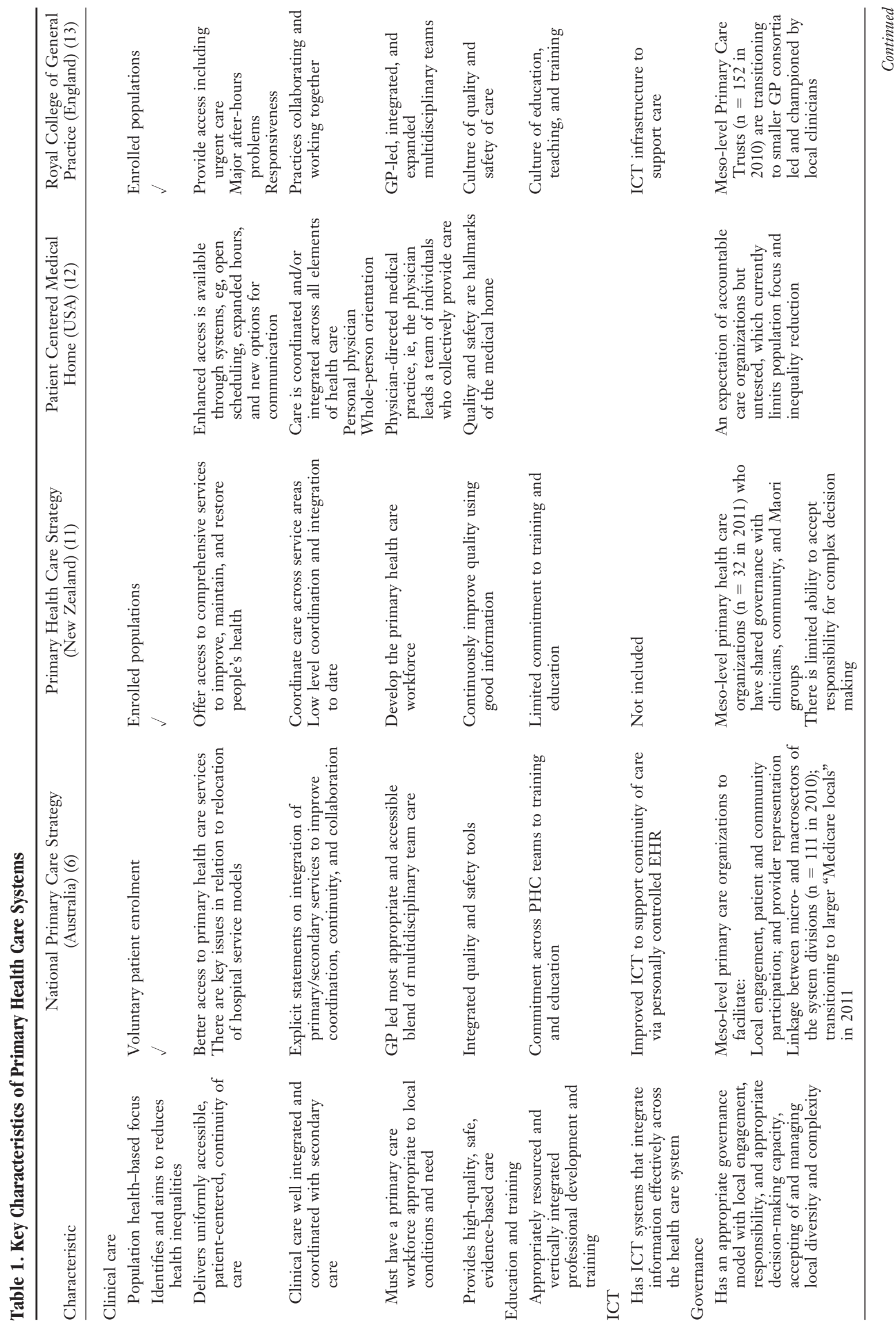




\section{Findings}

Since the early 1990s, PHC systems internationally have been reforming with the aim to improve population health outcomes, equity, access, and continuity and lower costs. Key characteristics of PHC systems are shown in Table 1.6,11-13

\section{PHC Organizations}

Twenty years ago, Australia established local "mesolevel" PHCOs (Divisions of General Practice), which are not a feature in the United States, as intermediate structures sitting between government and local PHC providers. They have assisted in changing the PHC landscape by creating population accountability, and they have a range of functions (Table 2). ${ }^{14,15}$

The need for Divisions arose in 1992 from within general practice to address the isolation and problems of fragmentation and marginalization and to provide a strong collective voice for general practices at a local level while allowing them to retain their independence. ${ }^{16}$ Divisions were controlled by GPs and funded by the federal government to provide better access and quality of care to local communities based on individual need. From 2009 a key building block for PHC reform was regional integration within $\mathrm{PHC}$ and between PHC and other sectors. ${ }^{17}$ Underpinning this reform was the evolution of Divisions to larger Medicare Locals, providing a key government platform to roll out the National Primary Health Care Strategy and allowing greater representation from the community and wider health professional groups, business, and management. ${ }^{18}$ PHCOs in Australia provide the necessary infrastructure to support the rollout of new national initiatives, which are discussed below.

\section{Improved Access to Services}

Improving access to multidisciplinary PHC teams able to deliver comprehensive care was a driving force for establishing Divisions. In 1995 Medicare access was extended to practice nurses and allied health professionals working with GPs in chronic disease management or aged care. The growth in numbers of non-GPs working in practices increased significantly; today $60 \%$ of general practices currently employ at least one practice nurse, with an average of 4 GPs per practice. ${ }^{19}$ The proportion of GP-patient encounters that involved a practice nurse more than doubled 


\begin{tabular}{|c|c|}
\hline Function & Activity \\
\hline \multicolumn{2}{|l|}{ Clinical care } \\
\hline Population health focus & $\begin{array}{l}\text { - Population health activities } \\
\text { - Community engagement } \\
\text { - Patient enrolment }\end{array}$ \\
\hline Reduce health inequalities & - Local initiatives, eg, Closing the Gap (Australia) \\
\hline Improve access & $\begin{array}{l}\text { - After-hours care } \\
\text { - Contracting with providers }\end{array}$ \\
\hline Integrated care & $\begin{array}{l}\text { - Disease management } \\
\text { - Coordinated and integrated service delivery }\end{array}$ \\
\hline Multidisciplinary workforce & - Access to GP-led expanded PHC teams \\
\hline Quality and safety & $\begin{array}{l}\text { - Clinical and practice support } \\
\text { - Monitoring quality and accreditation }\end{array}$ \\
\hline \multicolumn{2}{|l|}{ Integrated education and training } \\
\hline $\begin{array}{l}\text { Vertically integrated } \\
\text { professional development }\end{array}$ & - Multidisciplinary continuous professional development \\
\hline \multicolumn{2}{|l|}{$\begin{array}{l}\text { Integrated communications } \\
\text { technology }\end{array}$} \\
\hline Enhance clinical data sharing & $\begin{array}{l}\text { - Electronic discharge summary and referrals; personally } \\
\text { controlled electronic health record }\end{array}$ \\
\hline \multicolumn{2}{|l|}{ Integrated governance } \\
\hline Improve linkage & $\begin{array}{l}\text { - Act as link between macro- and microlevels of the system } \\
\text { - Link between primary and secondary sectors } \\
\text { - Link between "horizontal" components of the system, eg, } \\
\text { housing and employment }\end{array}$ \\
\hline Allocation of regional budgets & - Commissioning services \\
\hline Local/regional decision making & - Run by independent boards \\
\hline
\end{tabular}

GP, general practitioner; PHC, primary health care.

from $4.2 \%$ in 2005 to 2006 to $9 \%$ in 2009 to $2010 .^{19}$ Federal funding supports services provided by practice nurses, Aboriginal health workers, and other allied health professionals, for example, the Access to Allied Psychological Services program delivers packages of coordinated care for people with severe mental illness being managed in primary care. ${ }^{20} \mathrm{~A}$ broadened and integrated general practice clinical team was born.

\section{Integrated Clinical Care}

Divisions encouraged local networking between general practices and integrated general practice into the wider health system. They focused on meeting relevant primary care service gaps locally and practice support. Divisions provided core programs to address access, prevention, and early intervention; support integration and multidisciplinary care; and an increased focus on population health and the better management of chronic disease. For example, the Practice Incentive Program and Service Incentive Payment provided practices with funding for quality services such as immunization targets, quality prescribing, and diabetes management.

\section{Education and Training}

Divisions provide local multidisciplinary team education and training tailored to meet population needs. Although the Medicare Benefits Schedule (primary care items subsidized by the Australian government) has expanded to support multidisciplinary primary care services, there is still a shortage of health professionals, particularly in rural and remote areas. Responding to the GP shortage, federal and state governments have created more training places with the number of domestic medical graduates increasing from 1348 in 2005 to 2442 in 2012. This brings with it the need to expand capacity to deliver quality training and education. ${ }^{21}$

\section{High-Quality, Safe, Evidence-Based Care}

In Australia, $85 \%$ of general practices are independently accredited against the Royal Australian College of General Practice standards for general prac- 
tices (4th edition). ${ }^{22}$ Assisting practices to meet accreditation requirements has been a key role for Divisions. All GPs also undertake compulsory, ongoing quality improvement and continuing professional development supported by Divisions. In addition, $15 \%$ of general practices, with support from Divisions, have participated in the Australian Primary Care Collaboratives program (http://apcc.org. au/), a plan-do-study-act methodology developed at the Institute for Health Care Improvement (Boston, MA) and adapted for primary care in the United Kingdom by Sir John Oldham. Since 2004, collaboratives have engaged more than 1000 Australian general practices $(12 \%$ of all practices) in the improvement of diabetes and cardiovascular disease care and access, with results showing substantial improvement in participating practices. ${ }^{23}$

\section{Information Communication Technology}

Funding support via Divisions for information technology in general practice has supported one of the most computerized general practice sectors in the world ${ }^{24} ; 96 \%$ of practices in Australia currently are computerized. A key role for Medicare Locals is supporting the federal government's national electronic health record (allocated A $\$ 466.7$ million), scheduled to go live in July 2012. ${ }^{18}$ This will allow a person to more easily access their own health care information and make that information securely accessible to appropriate health care providers.

\section{Governance}

Fragmentation of health services, largely caused by the split between federal and state government funding responsibilities in Australia, has created a complex, rapidly changing, and often impersonal health system that is increasingly difficult and frustrating to navigate. ${ }^{15}$ To ensure Australia's health system is sustainable, safe, fair, and agile enough to respond to changing health needs, the National Health and Hospitals Reform Commission Report (2009) recommended governance change. ${ }^{25} \mathrm{~A}$ focus of the current reform package is to ensure the greatest use of the primary health care sector, thus easing the strain on acute hospitals. ${ }^{26}$ A key feature of Medicare Locals ${ }^{6}$ is to provide an overarching regional governance framework for primary health care via better integration and coordination of services within primary care and better linking of primary health care with other sectors. Medicare Locals will work closely with newly formed local hospital networks (LHNs) ${ }^{27}$ to identify and address local regional population needs ${ }^{28}$ and improve patient care and the quality and safety of health services.

Federal government plans describe how public hospitals will be brought together with Medicare Locals via LHNs to coordinate and integrate primary health care services, jointly aiming to better coordinate services within sectors. They are, however, currently short on detail about specific processes to integrate primary with secondary care. Integrated governance is key to successful health care integration. ${ }^{29}$ A single regional health entity has been proposed ${ }^{15}$ to align federal and state publicly and privately funded services with functions centered on integrated regional delivery of services (Figure 2). Without a regional approach to planning and care delivery, the split and potential for shifting costs and responsibilities may not be eliminated. ${ }^{30}$

A key governance challenge is to lead the health system in such a manner that all stakeholders understand the vision and priorities for change are supported in the process and, through mutual accountability, move toward a better, higher-performing health system. To assist with this change, health system performance assessments, including data from across the care continuum, is critical to aligning stakeholders and jointly holding them accountable. ${ }^{15,31}$

The development of integrated care may best be supported by increasing the use of incentives and financial flows to incentivize coordinated care, rather than the current system, which is designed primarily to pay for episodes of activity. ${ }^{32}$ Experience with local integrated systems in the United States, for example, Geisinger Health System and Kaiser Permanente, shows that high-quality communication and shared resources through alignment of incentives are models that could assist Australia to enable integration between Medicare Locals and the acute care sector. ${ }^{32,33}$

\section{Discussion}

The Australian health care system has been reforming progressively since the early 1990 s to inculcate primary care more significantly into coordinated health care delivery and address the schism between feder- 
Figure 2. Functions of regional health entities. ICT, information communication technology; NGo, nongovernment organization.

Regional Health Entity

Functions of Regional Health Entity

Measuremant Innovation Incentives Care Priorilies Professional Development Planning Integrated ICT Change Management Population Focus

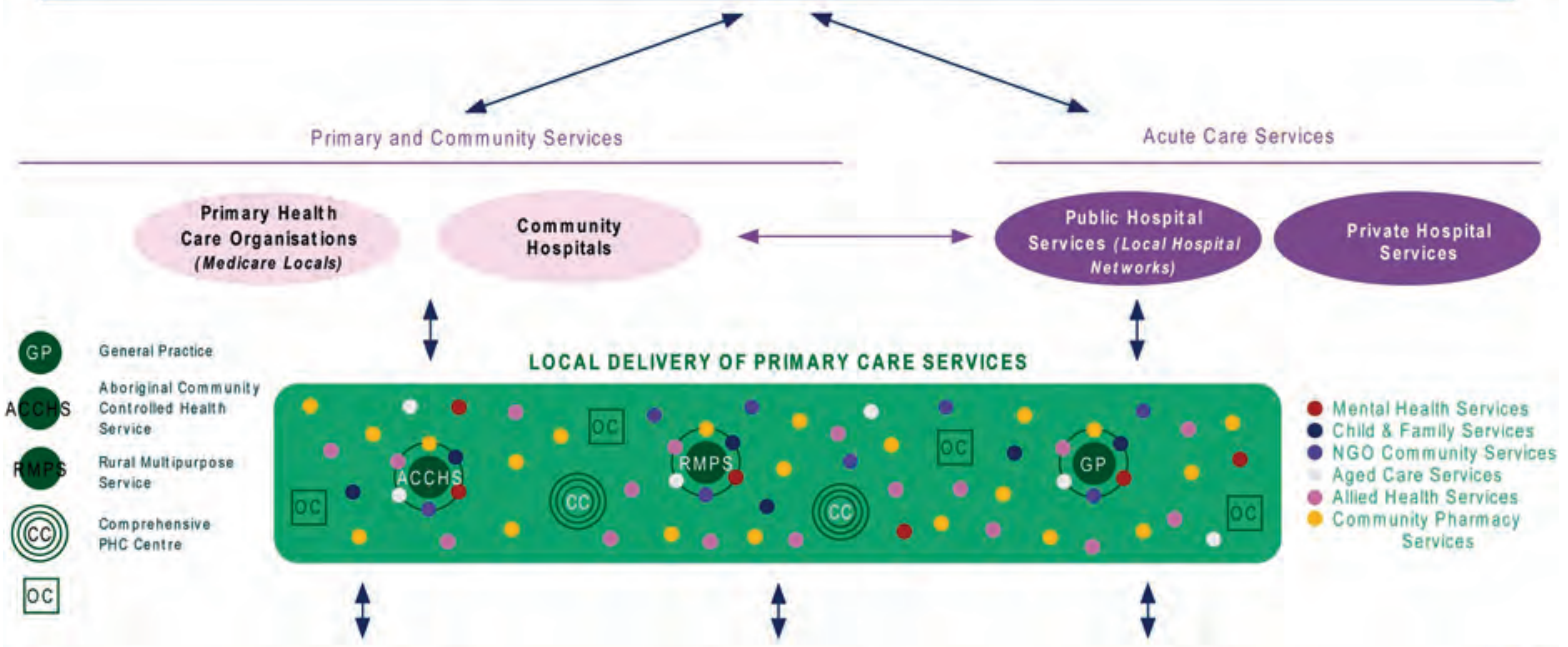

Individuals and Families

LOCAL POPULATION

Community Groups

ally and state-funded care. The incremental but persistent approach adopted by federal government in effecting this, along with the development of Divisions, has allowed engagement with the majority of Australian general practices and continued its patientcentered ethos. Investment in $\mathrm{PHC}$ infrastructure and meso-level PHCOs in Australia, as in other commonwealth countries, has provided capacity to impact PHC transformation significantly by focusing on population health, access to comprehensive services, multidisciplinary team-based education, implementation of quality improvement and prevention strategies, and integration of primary and secondary care (Table 1). The absence of such entities in the United States is striking and one of the more important lessons that we offer.

The national primary health care strategy, which affirmed the direction for PHC and informed the community of the value of good primary care, was a significant milestone in its evolution, and today the model of primary care stands tall against international benchmarks. Vital to future development is ensuring equitable access; growing the primary care workforce; addressing the increasing rates of chronic disease and high rates of obesity; and over- coming the fragmentation of funding and accountability by improving governance arrangements between current meso-level organizations to better deliver integrated services across the primary/secondary care boundaries.

We would like to thank Professor James Dunbar for providing the Australian Primary Care Collaboratives information.

\section{References}

1. Australian Government Department of Human Services. Medicare: for individuals. Available at http:// www.medicareaustralia.gov.au/public/index.jsp. Accessed May 27, 2011.

2. Starfield B, Shi L. Policy relevant determinants of health: an international perspective. Health Policy 2002;60:201-18.

3. Macinko J, Starfield B, Shi L. The contribution of primary care systems to health outcomes in OECD countries, 1970-1998. Health Serv Res 2003;38: $819-54$

4. World Health Organization Europe, Regional Office for Europe's Health Evidence Network. What are the advantages and disadvantages of restructuring a health care system to be more focused on primary care services? January 2004. Available at http:// 
www.euro.who.int/_data/assets/pdf_file/0004/74704/ E82997.pdf. Accessed October 18, 2011.

5. Commonwealth of Australia. National Health Strategy. The future of general practice. Issues paper no. 3. Canberra: Department of Health, Housing and Community Services; 1992.

6. Commonwealth of Australia. Building a 21st Century Primary Health Care System. Australia's First National Primary Health Care Strategy. Publication no. 6594. Canberra: Australian Government Department of Health and Ageing; 2010.

7. Muennig PA, Giled SA. What changes in survival rates tell us about US health care. Health Aff 2010; 29:2105-13.

8. Commonwealth of Australia. Primary Health Care Reform in Australia. Report to support Australia's First national Primary Health Care Strategy. Canberra: Australian Government Department of Health and Ageing; 2009.

9. Davis K, Schoen C, Schoenbaum SC, et al. Mirror, mirror on the wall: How the performance of the U.S. healthcare system compares internationally 2010 Update; 2010. Available at http://www.common wealthfund.org/ /media/Files/Publications/Fund $\%$ 20Report/2010/Jun/1400_Davis_Mirror_Mirror_ on_the_wall_2010.pdf. Accessed February 2, 2012.

10. Mays N, Pope C, Popay J. Systematically reviewing qualitative and quantitative evidence to inform management and policy-making in the health field. J Health Serv Res Policy 2005;10:S16-20.

11. Ministry of Health. The primary health care strategy. Wellington (NZ); February 2001. Available at http://www.health.govt.nz/publication/primaryhealth-care-strategy. Accessed February 2, 2012.

12. Robert Graham Center, Center for Policy Studies in Family Medicine and Primary Care. The patient centered medical home. History, seven core features, evidence and transformational change. November 2007. Available at http://www.aafp.org/online/etc/ medialib/aafp_org/documents/about/pcmh.Par. 0001.File.dat/PCMH.pdf. Accessed May 12, 2011.

13. Royal College of General Practitioners. The future direction of general practice: a roadmap. London: Royal College of General Practitioners; 2007. Available at http://www.rcgp.org.uk/pdf/CIRC_RCGP\% 20Roadmap\%20Future\%20General\%20Practice\% 2013th\%20Sept\%202007.pdf. Accessed May 12, 2011.

14. Gardner K, Douglas KA, Gear A, et al. Primary Health Care Position Statement: A scoping of the evidence. An update for 2009. Canberra: Australian Primary Care Health Research Institute; 2009. Available at http://www.agpn.com.au/_data/assets/ pdf_file/0017/16271/20090402_pos_AGPN-PHCPosition-Statement-2009---APHRCI-scoping-ofevidence.pdf. Accessed February 2, 2012.

15. Jackson CL, Nicholson C, McAteer EP. Fit for the future-a regional governance structure for a new age. Med J Aust 2010;192:284-7.
16. Hutton C. Divisions of general practice, capacity building and health reform. Aust Fam Physician 2005;34:64-6.

17. Commonwealth of Australia. Building a 21st Century Primary Health Care System. A draft of Australia's First National Primary Care Strategy. Publication no. P3-5479. Canberra: Australian Government Department of Health \& Ageing; 2009.

18. Department of Health \& Ageing. Medicare Locals. Discussion paper on governance and functions. Canberra: Australian Government; 2010. Available at http://www.yourhealth.gov.au/internet/yourHealth/ publishing.nsf/Content/MedicareLocalsDiscussion Paper/\$FILE/Discussion\%20Paper.pdf. Accessed October 24, 2011.

19. Britt H, Miller GC, Charles J, et al. General practice activity in Australia 2009-10. General practice series no. 27. Cat. no. GEP 27. Canberra: Australian Institute of Health and Welfare; 2010.

20. McDonald J, Harris M, Cumming J, Powell-Davis G, Burns P. The implementation and impact of different funding initiatives on access to multidisciplinary primary health care and policy implications. Med J Aust 2008;188:S69-72.

21. Fox GJ, Arnold SJ. The rising tide of medical graduates: how will postgraduate training be affected? Med J Aust 2008;189: 515-8.

22. The Royal Australian College of General Practitioners (RACGP). RACGP Standards for general practices 4th edition. Melbourne: RACGP; 2010. Available at http://www.racgp.org.au/standards/contents. Accessed May 5, 2011.

23. Ford D, Knight AW. The Australian primary care collaboratives: an Australian general practice success story. Med J Aust 2010;193:90-1.

24. Schoen C, Osborn R, Doty MM, Squires D, Peugh J, Applebaum S. A survey of primary care physicians in 11 countries, 2009: Perspectives on care, costs, and experiences. Health Aff 2009;28:w117183. Available at http://content.healthaffairs.org/ content/28/6/w1171. full?sid=135b3b76-60e8-4c238b64-f15f149f542e.

25. Commonwealth of Australia. A Healthier Future For All Australians-Final Report of the National Health and Hospitals Reform Commission. June 2009. Available at http://www.yourhealth.gov.au/internet/ yourhealth/publishing.nsf/Content/nhhrc-report. Accessed February 2, 2012.

26. Council of Australia Governments. Heads of Agreement-national health reform. 2011. Available at http://www.coag.gov.au/coag_meeting_outcomes/ 2011-02-13/docs/communique_attachmentAheads_of_agreement-national_health_reform_ signatures.pdf. Accessed May 14, 2011.

27. Roxon N. Local Hospital Networks to deliver on local needs. March 3, 2010. Available at http:// www.health.gov.au/internet/ministers/publishing. 
nsf/Content/mr-yr10-nr-nr042.htm. Accessed May 12, 2011.

28. Leutz W. Reflections on integrating medical and social care: five laws revisited. J Integr Care 2005;13:3-12.

29. Smyth L. Making integration work requires more than goodwill. Healthc Q 2009;13:S43-8.

30. Hall J. Designing the structure for Australia's health system. Occasional paper. January 2010. Canberra: Academy of Social Sciences Australia; 2010.

31. World Health Organization. Assessing system performance for health governance. March 2011. Avail- able at http://www.euro.who.int/_data/assets/pdf_ file/0012/134301/10E_-HSPA-wrking-paper-unedited. pdf. Accessed May 14, 2011.

32. Ham C, Smith J. Removing the policy barriers to integrated care in England. London: The Nuffield Trust; 2010. Available at http://www.nuffieldtrust. org.uk/members/download.aspx? $\mathrm{f}=/$ ecomm/files/ Removing_the_Policy_Barriers_Integrated_Care. pdf. Accessed May 15, 2011.

33. Zwar NA. Health care reform in the United States: an opportunity for primary care? Med J Aust 2010;192:8. 